\title{
ÁLVARO CUNQUEIRO COMO INTELECTUAL DO FRANQUISMO
}

\section{Olivia Rodríguez González}

Universidade da Coruña

doi:10.17075/mucnoc.2014.016 

Forcadela, M. / T. López / D. Vilavedra (coords.) (2014): Mil e un cunqueiros. Novas olladas para un centenario, Santiago de Compostela, Consello da Cultura Galega. doi:10.17075/mucnoc.2014. pp. 329-340

\section{UN INTELECTUAL NO SEU TEMPO}

No mundo da literatura, enténdese por intelectual o escritor ao servizo da sociedade, cunha toma de postura evidente no mundo en que participa, e mesmo guieiro de conciencias. A figura do poeta guieiro calla no s. XIX como produto da Ilustración e tomando o relevo dunha función que ata entón asumía para si o clero. O proceso culmina coa contribución de Émile Zola no «Caso Dreyfus». Neste sentido, non podemos negar que Cunqueiro foi un intelectual ao servizo da Nova España desde que comeza a súa actividade en Era Azul de Ortigueira. O máis brumoso da biografía intelectual de Álvaro Cunqueiro é a fase da primeira posguerra. A súa traxectoria desde a preguerra é similar á de Gonzalo Torrente Ballester, entre outros, pois únese á Falanxe vitoriosa, despois de pasar polas filas do Partido Galeguista. Nos comezos como falanxista e xornalista, traballa firme para facerse cun currículo de afecto ao Réxime e construtor da Nova España: en Era Azul, Vértice, La Nueva España, Santo y Seña e outras revistas.

Con esta bagaxe, acompaña os camaradas na toma de Madrid na primavera de 1939, ocupando como xornalista as cabeceiras da prensa derrotada —no seu caso, o monárquico ABC. A vida en Madrid é dura daquela, e todos, individuos e faccións, xogan a gañar e situarse. Mortos ou exiliados os intelectuais roxos, tratan os falanxistas do grupo de Burgos, unidos aos carlistas vasco-navarros, de recuperar o ambiente falanxista do Madrid de preguerra - moi ben retratado en Madrid de corte a checa (1938), do conde de Foxá, aquel que deixou dito: «Fagamos de España un país fascista e marchemos a vivir ao estranxeiro». Daquela, o Enterrador - así era alcumado José Antonio Primo de Rivera pola cantidade de adolescentes aos que mandaba enfrontarse con pistolas para acabar morrendo (Foxá 1938 [1993: 99]) — reuníase nos faladoiros co máis selecto do novo partido e adláteres, como Agustín de Foxá e Eugenio Montes, pero tamén co mellor da vangarda republicana, Federico García Lorca, Rafael Alberti e Teresa León. Xuntos crearían un estilo, o de Eugenio Montes, Ernesto Giménez Caballero, Luys Santamarina, Samuel Ros, que sería tamén o de Álvaro Cunqueiro ou José 
María Castroviejo, e que está na mesma cerna do estilo de José Ortega y Gasset e do primeiro Max Aub.

Cunqueiro fai nestes círculos unha carreira meteórica de xornalista de propaganda, xa antes de chegar a Madrid. Na capital, empeza a ter problemas. Aínda non se sabe que pasou para que tan axiña o botasen do ABC. Segundo a lenda máis estendida, vendeu as máquinas de escribir da Redacción; igual que se contaba que, anos despois, tivo que marchar de Madrid por deixar tirado na estación de Irún ao xefe da Gestapo e ministro do Interior alemán, Heinrich Himmler. Cunqueiro optou en Burgos por desviarse a Mondoñedo e gastar en comedelas as trinta mil pesetas (algúns din que 50 mil) que Ramón Serrano Súñer lle deu para a operación. Entre os feitos divulgados polas diversas lendas que teñen como protagonista o escritor, está comprobado e divulgado por Franco Grande o de que a Cunqueiro o expulsaron de Falanxe por unha estafa de compra de papel para o editor Luis de Caralt. E que lle foi retirado o carné de xornalista por unha estafa á embaixada de Francia na persoa do agregado cultural ao cobrar por anticipado un suplemento para a cabeceira católica Misión, revista que, dito sexa de paso, nunca lles pagaba aos colaboradores (Franco 1991) ${ }^{1}$. A partir dese momento, Cunqueiro sobrevive con colaboracións asinadas con nomes distintos, como tradutor para o teatro, etc. Para saír das angustias económicas que o matrimonio e a paternidade recente lle supoñen, chega a cometer accións delictivas (en 1944, en 1946 e ata tres en 1947); a última será a «apropiación indebida» de alfaias e do produto da venda duns carruseis propiedade dunha señora chamada Carmen Prida Casas. As causas seguiríano unha vez lonxe, pois, en 1951, a Audiencia Territorial de Madrid «interesa a averiguación do seu domicilio» e, en maio, o Goberno Civil de Lugo comunica que é ingresado na Prisión Provincial ${ }^{2}$.

1 A fonte documental reprodúcese en apéndice final e aparece así citada ao comezo do traballo: «Na Dirección General de Prensa existe un expediente de trinta e seis páxinas, onde se poden (sic) atopar algunha noticia que o biógrafo de Cunqueiro non pode deixar de esguello [...]. Non faltará quen pense que mellor fora deixar esas follas durmindo onde ata agora durmían [...]».

2 A Dirección General de Seguridad responde a unha petición do Ministerio de Información y Turismo enviando un informe datado o 23 de febreiro de 1973 sobre o xornalista Álvaro Cunqueiro, que "presta sus servicios» nese momento na revista Destino. Nese informe, apúntanse os sumarios instruídos ("Âlvaro Cunqueiro»), Archivo General de la Administración del Estado). 
Tampouco non é o castigo de Cunqueiro un caso insólito no seu círculo: é deportado a Mondoñedo de igual xeito que, salvando as distancias relativas aos motivos, o foi a San Cugat Dionisio Ridruejo ou como foi obrigado Camilo José Cela a deixar Madrid. Ambos os dous, tamén con retirada do carné e expulsión da Asociación da Prensa. Igual que a Cunqueiro, nada lles impediu seguir coa súa carreira fóra da capital, e nada lles impediu asinar textos con pseudónimo. Tratábase, por outra banda, de penados con privilexios do Réxime.

\section{A APERTURA CORUÑESA}

En 1950, un grupo de cincuenta escritores e artistas da Coruña aceptan a idea de Pascual-Luis Gantes de Boado, católico aspirante a diplomático, de fundar unha Asociación de Cultura Iberoamericana (ACI). A ACI coruñesa nace como entidade colaboradora e adherida ao Instituto de Cultura Hispánica, que se fundara en El Escorial durante a celebración do Congreso da Pax Romana en xullo de 1946. Entre os socios desa ACI, uns cantos - MarianoTudela, Antonio Molina, Fernando Mon, Francisco Tudela e Raúl Calvimontes_ pretende sacar o admirado xornalista do ostracismo que sufría en Mondoñedo. Saben que Cunqueiro estaba realmente encarcerado no xulgado de Mondońedo: o xuíz, Enrique Pérez Ardá, deixábao libre pola mañá e a iso das sete da tarde ía buscalo ao casino para dicirlle que tiñan que dar o seu paseo xuntos. O paseo consistía en ir ao xulgado, onde se atopaba tamén o cárcere, para pasar a noite (Rodríguez 2004).

A Asociación Cultural Iberoamericana da Coruña estaba integrada por intelectuais de corte liberal, e moi ben protexida por elementos fortes do Instituto de Cultura Hispánica, institución que o Ministerio de Asuntos Exteriores utilizaba para estender as ideas nacionalcatólicas da hispanidade por Iberoamérica, mentres en Europa o Réxime seguía política e economicamente illado. Cando España é acollida posteriormente como baluarte antimarxista útil na guerra fría, utilizaranse as armas de colonización cultural do Réxime para contrarrestar os movementos revolucionarios hispanoamericanos. Entre os nomes figuran Joaquín Ruiz Jiménez, Pedro Laín Entralgo, Leopoldo Panero, Alfredo Sánchez Bella, Carlos Robles Piquer e Manuel Fraga Iribarne. Cando este se atope no cargo de 
ministro de Información e Turismo, entre 1962 e 1969, dará especial cobertura, a cambio de servizos diversos, á rede de xornalistas e escritores tecida desde o Instituto de Cultura Hispánica. Se a ACI coruñesa puido facer cultura heterodoxa durante as diferentes fases da súa existencia (1951-1976), foi aproveitando ese amparo. Pero, tamén, grazas á existencia de elementos culturais superviventes da época da República, que exercían certo poder na sombra ou se refuxiaban nas varias modalidades que se cońecen do exilio interior (tal foi o caso de Álvaro Cebreiro e da bohemia de artistas como Pepín Béjar ou Urbano Lugrís) ${ }^{3}$.

Foron as da ACI da Coruña as primeiras conferencias que deu Álvaro Cunqueiro logo do seu confinamento, e moi ben pagadas, abofé, pois recibía 1000 pesetas, o duplo que os demais conferenciantes. Cada vez eran máis frecuentes e Cunqueiro pasaba días, ás veces unha semana, entre amigos. Os artigos que comezou a escribir para $\mathrm{La}$ Voz de Galicia fixérono moi popular na cidade, onde recibía homenaxes en forma de grandes xantares. En 1959, o Teatro de Cámara da ACI estreou no Colón $O$ incerto señor don Hamlet, unha difícil recreación edípica da traxedia shakespeariana. Unha denuncia por inmoralidade na Delegación do MIT estivo a piques de abortar a representación (Cunqueiro 2003: 73; Cabana 2007; Avilés 1991). De novo, a protección desde Madrid fixo que se puidese representar — como catro anos despois, en 1963, podería verse, dentro do Programa de Festivales de España na praza de touros da Coruña, Os vellos non deben de namorarse, sen que ninguén o impedise. Os fillos da burguesía cultivada e bohemia desta cidade nunca deixaron de estar mal vistos e de xeraren problemas de tipo político e económico. Tras o peche dunha revista do seu ámbito, Atlánti$d a$, durante a crise política de 1956, algúns dos seus membros máis activos emigraron a Madrid, de novo «rompeolas de todas las Españas». A ACI continuaría con forza baixo a batuta de Miguel González Garcés e o visto e prace protector da chamada «Era Fraga».

Se facemos unha lista de conferenciantes convidados pola ACI da Coruña, atoparemos nela os nomes de Leopoldo Panero, Luis Rosales, Gerardo Diego, Manuel Fraga Iribarne, José Luis Varela, Francisco Serrano Castillo, Benito Varela Jácome, Carlos Martínez Barbeito, Gonzalo Torrente Ballester, Camilo

3 Figuras levadas á idealización literaria por Manuel Rivas en Os libros arden mal (2006) e por Luís ReiNúñez en O señor Lugrís e a negra sombra (2007). 
Barcia Trelles, Manuel María, Uxío Novoneyra, Dionisio Gamallo Feirros, Julio Sigüenza, José María Castroviejo, Ángel del Castillo, Ramón Otero Pedrayo, Camilo José Cela, Mariano Tudela, Ramón Nieto, Daniel Sueiro, Silvio Santiago, Valentín Paz-Andrade, Juan Rof Carballo, Antonio López Veiga, Francisco Fernández del Riego, Celso Emilio Ferreiro, José María Moreno Galván, Xesús Alonso Montero, etc. (ACI).

\section{A «ERA FRAGA»}

Os anos de Fraga no MIT (1962-1969) trouxeron beneficios a todos os escritores e xornalistas galegos que colaboraron coas institucións da hispanización americana. No caso de Álvaro Cunqueiro, abonda con lembrar a dirección de Faro de Vigo (en cuxo logro tamén interveu Manuel Cerezales), tras a restitución do carné de xornalista e ata que abandona o posto coas novas normas que impoñía a aplicación da Lei de prensa de 1966. Cunqueiro corresponde participando como intelectual no programa turístico ideado por Fraga, mesmo viaxa a América para tomar outra praza política: o Centro Galego de Bos Aires, cuxa directiva é arrebatada aos antifranquistas en 1966. Logo recuperaríana os republicanos, pero, no intervalo, José Blanco Amor era nomeado director da revista Galicia, cuxa imaxe moderniza moi ao gusto das publicacións do Ministerio Español de Información e Turismo. Desde alí, este xornalista e escritor nado en Bergondo (A Coruña) e emigrado á Arxentina con 21 anos maniféstase en "Cartas del director» deste xeito: «la actitud de xenreira que se adoptó en el pasado, ya no sirve para el presente y servirá aún menos para el futuro [...]. Nuestra tierra no puede ser una isla cultural en un mundo que se transforma velozmente en un universo integrado» (Blanco 1967b).

Recrútanse logo novas sinaturas e convídanse conferenciantes, acordes todos coa nova liña ideolóxica: á beira de Jorge Luis Borges e algún outro autor arxentino amigo seu, aparecen os nomes de Juan Naya, José María Castroviejo, Manuel Casado Nieto, Vicente Risco, Gerardo Diego, José Luis Varela e Álvaro Cunqueiro. Sobre o último escribe José Blanco Amor: «Este hombre no había sido invitado hasta ahora porque se practicaba aquí precisamente una política discriminatoria» (Blanco 1967a). 


\section{RELACIÓNS DE ÁLVARO CUNQUEIRO CON VICENTE RISCO E CON CAMILO JOSÉ CELA NO CAMPO LITERARIO DO FRANQUISMO}

A xeito de mostra de relacións entre intelectuais do franquismo, daremos unhas notas sobre as que A. Cunqueiro mantivo con Risco e con Cela.

O maxisterio de Vicente Risco foi recońecido por Álvaro Cunqueiro xa desde a época de Nós e o Partido Galeguista. Vémolos coincidir os dous escritores na revista Misión, nos faladoiros das estadías de ambos os dous en Madrid, na revista vinculada á ACI coruñesa, Atlántida. A primeira é unha revista de Acción Católica que en Ourense fundaron, entre outros, Ramón Otero Pedrayo e Vicente Risco, e que empezou dirixindo Ricardo Outeirińo (1937-1939). Cunqueiro colaboraba con pseudónimos como "Álvaro Labrada». Nos anos en que este reside en Madrid, a revista acababa de trasladarse á capital desde Pamplona, onde Vicente Risco e Manuel Cerezales, o seu director daquela, se encargaron a partir do final da guerra de sacala do prelo da cabeceira carlista Pensamiento Navarro (1939-1940). Na capital tomada, pasaría a ser dirixida por José Luis Peña Ibáñez (1941-1947), o que fora director de La Nueva España de San Sebastián. Vicente Risco áchase en Madrid desde 1945 escribindo para Informaciones, do que é subdirector o amigo Manuel Cerezales, un carlista e intelectual moderado, con grandes dotes para a crítica literaria. Como deixamos apuntado, en Faro de Vigo será, abofé, Cerezales un dos que aconsellan o nome de Álvaro Cunqueiro para sucedelo como director en 1962.

Cunqueiro coincide nas actividades da ACI coruñesa con Vicente Risco, pero só a través da revista Atlántida, pois Risco non adoita viaxar daquela á Coruna para participar en actos culturais. O escritor de Mondoñedo non se cansará de repetir en artigos e conferencias que considera a Risco, á beira de Mircea Eliade, como a máxima autoridade no tratamento do mito. Vicente Risco, que goza daquela de gran prestixio cultural - fóra do círculo do nacionalismo galego, onde o teñen por traidor e non dubidan en poñer reparos á recuperación para Galaxia na que se empeñou Paco del Riego-, ten como unha das súas múltiples tarefas a crítica literaria en La Región. Nas recensións dedicadas a Álvaro Cunqueiro nos anos 50 e 60, celébrao Risco como narrador que pode facer fronte ao deprimente realismo imperante na literatura española e estranxeira. Contra a actitude dogmática e preceptista dalgúns dos partidarios da literatura realista, que ven no rebordar de 
imaxinación de Cunqueiro unha actitude de evasión, responde Risco que «unha actitude de evasión é tamén unha actitude propia do noso tempo, é unha maneira abondo clara de encarar a realidade presente, que non é toda a realidade».

Por outra banda, a relación entre Cunqueiro e Cela establécese entre ambos os dous de igual a igual, en calidade de colegas. Camilo José Cela intenta fuxir á Coruña nos anos máis baixos da súa carreira en Madrid, cidade onde, por suposto, ambos os dous escritores coincidiron. Cando viaxa en coche da Falanxe (Rodríguez 2004) ${ }^{4}$ a Galicia para escribir o libro de viaxes Del Miño al Bidasoa, que se publica en 1952, non deixa de visitar Mondońedo e anotar o seu encontro co Cunqueiro alí confinado, esperando volver — comentario que parece estar apuntando á súa situación de confinamento-: gústalle ao vagabundo a calma de Mondoñedo e os paseos polas rúas bebendo viño nas baiucas, «y hablando de mitología celta y de los caballeros de la corte del rey Artús con don Álvaro, que es un hombre sin prisas, como su pueblo, que es un hombre que conoce las esotéricas ciencias de la espera, las revueltas y complejas artes de la espera» (Cela 1952 [1981:44]).

Pola noite, visita o parladoiro da rebotica no que escoita «las explicaciones sobre los caballeros de la Tabla Redonda que regala don Álvaro, de quien ya el vagabundo habló, un señor muy culto que es escritor, poeta y pescador de truchas, que en el país dicen troiteiros» (Cela 1952 [1981: 47]).

Unha vez elixida Palma de Mallorca como residencia e plataforma do seu lanzamento como escritor, Cela funda Papeles de Son Armadans en 1956. A revista é tamén editorial e Cela proxecta unha colección de poesía galega que quere chamar «Juan Rodríguez del Padrón». Ten como intermediario —el dirá cónsul- a Celso Emilio Ferreiro en Vigo, que é quen volve pońelo en contacto con Francisco Fernández del Riego, pois os dous, da «quinta do 37», estiveron na mesma compañía durante a Guerra Civil, no bando nacional, como proba a documentación epistolar da Fundación Penzol (Cela 1939)5. Ferreiro tamén o pon en contacto cos irmáns Álvarez Blázquez —Emilio, Darío, Xosé María—, cos que mantivera relación Cela de neno durante as estadías en Tui coa familia. Pois

4 «Yo lo conocí [a Cela] cuando vino [a Galicia] en un coche de la Falange para escribir Del Miño al Bidasoa».

5 Carta mecanografada de Camilo José Cela a Del Riego datada o «día del Carmen del Año de la Victoria» en Iria-Flavia. Agradézolle a María García Liñeira a referencia exacta no Arquivo da Fundación Penzol. 
ben, os primeiros nomes que Celso Emilio lle dá a Cela para abrir con dignidade a colección son os de Aquilino Iglesia Alvariño e Álvaro Cunqueiro. Estamos no verán de 1956. Cela celebra poder contar cos versos orixinais de Cunqueiro e pídelle a Celso Emilio que os revise para comprobar que son inéditos. Que non o deixe de man, porque:

[...] a Álvaro conviene vigilarlo, ya que la probidad —incluso la probidad intelectual— no es su fuerte. Me alegra tener este texto suyo, ya que lo aprecio mucho como poeta, y sólo lamento que un hombre de su innegable talento se pierda en trampas y cominerías, como las oficiosas y estúpidas que sobre mí hizo en la Hoja del Lunes de La Coruña. Pero pienso que la literatura y el pensamiento gallego deben estar por encima de la minúscula anécdota. Envíame enseguida, te repito, su libro que será publicado con todos los honores (Cela 1956a).

Máis adiante, cando Celso Emilio Ferreiro lle transmite unha especie de desculpa de Cunqueiro polo acontecido, Cela di dar por rematado o incidente e opina: «es un gran escritor envuelto en una mísera envoltura humana» (Cela 1956b).

Caravaneiro da i-alba i-outros poemas é o libro que envía a Papeles de Son Armadans e que nunca se publicará porque, por falta de presuposto e subscritores suficientes, a colección «Juan Rodríguez del Padrón» queda en proxecto fanado. Será devolto o orixinal ao poeta.

En 1960, despois dunha confusión propiciada desde Vieiros na noticia da intervención de Cela na RAE para cambiar unha das acepcións denigratorias de gallego, a referente ao idioma, e ante as dificultades e atrancos que atopa para publicar a tradución para o galego, realizada por Vicente Risco e prologada por R. Otero Pedrayo, de La familia de Pascual Duarte, Cela declara estar farto: «La Galicia capitaneada polos Cunqueiro e Castroviejo - y la Galicia del resentimiento y la adoración al poder constituído- me es hostil y no pierde ocasión de desvirtuar los hechos» (Cela 1960).

Pola súa parte, Álvaro Cunqueiro dirá publicamente, anos despois, do escritor padronés:

La literatura actual de Cela no tiene interés ninguno. Camilo José es un buen amigo mío; yo le admiro y lo considero como uno de los grandes maestros del idioma español, al que sabe exprimir con firmeza y violencia a la vez. Ahora bien, todo este mundo del 
tremendismo en que se halla metido es como una pescadilla que se muerde la cola. Algunas de sus obras, concretamente Viaje a la Alcarria y un par de ellas más, son muy buenas. Pero el resto, aun con tener el éxito editorial que tiene ahora, en el futuro no creo que las lea nadie (Cunqueiro 1965).

\section{FINAL}

O narrado pretende servir de mostra e recordatorio de vidas e actitudes intelectuais que no presente aparecen esvaídas polo maior peso que na investigación histórica se deu nos últimos anos á reconstitución do sistema literario galego na resistencia durante a ditadura. Debemos empezar agora a despexar as brumas da Galicia literaria do franquismo se non queremos transmitir a idea dunha Galicia entre 1939 e 1975 na que primaba o antifranquismo interior e as traxectorias vitais do exilio republicano e nacionalista. Cando o panorama estea máis ou menos completo, entón haberá que confrontar as distintas parcelas do campo cultural da posguerra. Daquela teremos que explicar a convivencia, relacións de apoio ou confrontación de escritores de distintas linguas literarias e distintos posicionamentos ideolóxicos nas diversas xeografías culturais galegas. 


\section{FONTES DOCUMENTAIS CITADAS}

ACI, Arquivo do Reino de Galicia, Cultura.

"Átvaro Cunqueiro", Archivo General de la Administración, Cultura.

Avilés de Taramancos, Antonio: «Don Hamlet no paredón», Seiva, 4, maio de 1991: 79-82.

Blanco Amor, José: «Cartas del Director», Galicia, 556, Bos Aires, 6-7 de 1967a: 1.

Blanco Amor, José: «Cartas del Director», Galicia, 558, Bos Aires, 11-12 de 1967b: 9.

Cabana, Darío Xohán: Cunqueiro e Don Hamlet en Lugo (San Froilán, 1959), Lugo, Concello de Lugo, 2007.

Cela, Camilo José: Carta a Francisco Fernández Del Riego, 16/07, Arquivo Fundación Penzol en Vigo,

FR-CA-007/020, 1939.

Cela, Camilo José: Del Miño al Bidasoa. Notas de un vagabundaje, Barcelona, Noguer, [8a ed., 1981].

Cela, Camilo José: Carta a Celso Emilio Ferreiro, 22/07, Arquivo da Fundación Camilo José Cela en Iria Flavia, 1956a.

Cela, Camilo José: Carta a Celso Emilio Ferreiro, 06/08, Arquivo da Fundación Camilo José Cela en Iria Flavia, 1956b.

Cela, Camilo José: Carta a Celso Emilio Ferreiro, 29/01, Arquivo da Fundación Camilo José Cela en Iria Flavia, 1960.

Cunqueiro, Álvaro: «Entrevista», La Nueva España, Oviedo, 13/03/1965: 8.

Cunqueiro, Álvaro: Cartas ao meu amigo. Epistolario mindoniense a Francisco Fernández del Riego (1949-1961), edición de Dolores Vilavedra, Vigo, Galaxia, 2003.

FoxÁ, Agustín de: Madrid de Corte a checa, Salamanca, Jerarquía, 1938 [Barcelona, Planeta, 1993].

Franco Grande, Xosé Luís: «Expulsión e readmisión do periodista Álvaro Cunqueiro», A Trabe de Ouro, 8, outubro/novembro/decembro 1991, pp. 563-572.

Rodríguez GonzÁlez, Olivia: «Entrevista a Paco Tudela» (gravación inédita), marzo de 2004. 